Supporting Information

\title{
Marinobacter sp. Stable Hydrous Titanium Oxide Functionalized Bovine Serum Albumin Nanospheres for Uranium Capture from Spiked Seawater
}

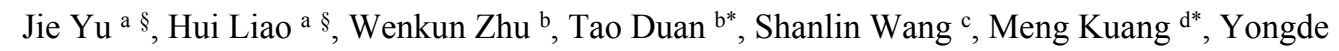
Zhang ${ }^{c}$, Xiaoyan Lin ${ }^{\mathrm{b}}$, Xuegang Luo ${ }^{\mathrm{a}}$, and Jian Zhou ${ }^{\mathrm{a}^{*}}$

a National Collaborative Innovation Center for Nuclear Waste Disposal and Environmental Safety, School of Life Science and Engineering, Southwest University of Science and Technology, Mianyang, Sichuan 621010, PR China.

${ }^{\mathrm{b}}$ State Key Laboratory of Environment-friendly Energy Materials, School of National Defense Science and Technology, Southwest University of Science and Technology, Mianyang, Sichuan, 621010, PR China

${ }^{c}$ Institute of Computer Application, China Academy of Engineering Physics, Mianyang, Sichuan, 621900, PR China

d Institute of Cotton Research, Chinese Academy of Agriculture Sciences/ Zhengzhou Research Base, State Key Laboratory of Cotton Biology, Zhengzhou University, Zhengzhou 450001, PR China

§These authors contributed equally to this work and should be considered co-first authors.

*Corresponding author: Jian Zhou, National Collaborative Innovation Center for Nuclear Waste and Environmental Safety, School of Life Science and Engineering, Southwest University of Science and Technology, Mianyang, 621010, PR. China.

E-mail address: zhoujian@,swust.edu.cn (J. Zhou). 
S1. The media formula of Marinobacter sp.

Table S1 The media formula for Marinobacter $s p$.

\begin{tabular}{cccc}
\hline Nutrient & Weight $(\mathrm{g})$ & Distilled water $(\mathrm{mL})$ & $\mathrm{pH}$ \\
\hline Yeast extract & 5 & & \\
Peptone & 10 & 1000 & 7 \\
$\mathrm{NaCl}$ & 30 & & \\
\hline
\end{tabular}

S2. Marinobacter sp. microbial stability.
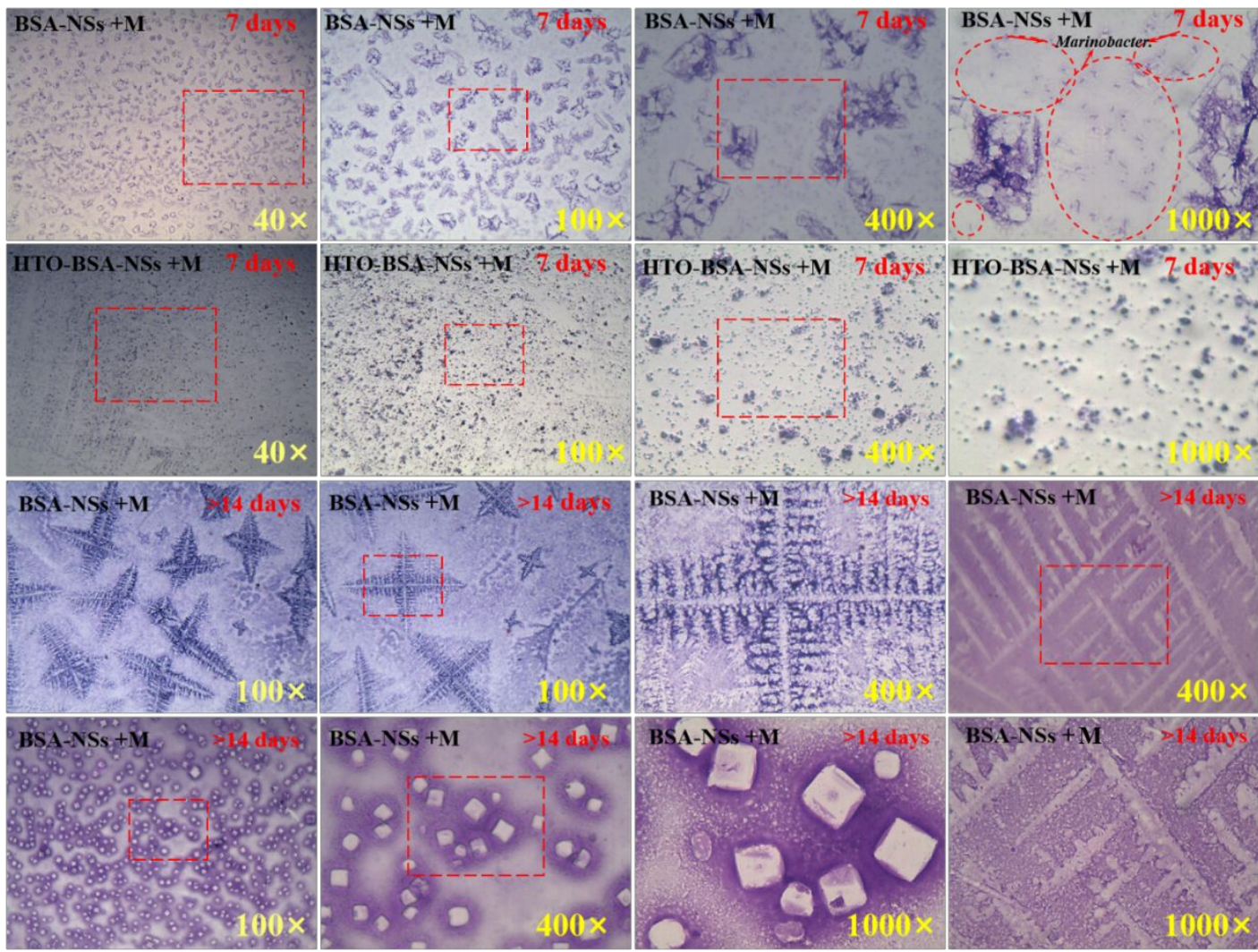

Figure S1 Microscope images of cultures

\section{S3. Isotherm models fitting:}


Experimental data was fitted by Langmuir and Freundlich models. The linear and non-linear form of Langmuir isotherm equation can be written as:

$$
\begin{aligned}
& \frac{C_{\mathrm{e}}}{\mathrm{q}_{\mathrm{e}}}=\frac{1}{K_{L} \mathrm{q}_{\max }}+\frac{C_{\mathrm{e}}}{\mathrm{q}_{\max }} \quad \text { (linear) } \\
& \mathrm{q}_{e}=\frac{q_{\max } K_{L} C_{e}}{\left(1+K_{L} C_{e}\right)} \quad \text { (non-linear) }
\end{aligned}
$$

The Freundlich Model can be expressed as linear and non-linear forms:

$$
\begin{aligned}
& \ln q_{e}=\ln K_{F}+\frac{1}{n} \ln C_{e} \quad \text { (linear) } \\
& q_{e}=K_{F} C_{e}^{\frac{1}{n}} \quad \text { (non-linear) }
\end{aligned}
$$

where $q_{e}\left(\mathrm{mg} \mathrm{g}^{-1}\right)$ represents the equilibrium adsorption of uranium (VI) on the adsorbent, $C_{0}$ and $C_{e}\left(\mathrm{mg} \mathrm{L}^{-1}\right)$ are initial and equilibrium uranium (VI) concentration, respectively.

\section{S4. Kinetics models fitting:}

Two kinds of kinetic models, pseudo-first-order and pseudo-second-order, were employed to evaluate the rate-controlling mechanism of the adsorption process. The linear and non-linear forms of the equations are given as follows:

$$
\begin{aligned}
& \ln \left(q_{e}-q_{t}\right)=\ln q_{e}-K_{1} t \\
& \frac{\mathrm{t}}{q_{t}}=\frac{t}{q_{e}}+\frac{1}{K_{2} q_{e}^{2}}
\end{aligned}
$$

The non-linear forms of pseudo-first-order and pseudo-second-order kinetic models can be written as:

$$
\mathrm{q}_{t}=q_{e}\left(1-\exp \left(-K_{1} t\right)\right)
$$


$\mathrm{q}_{t}=\frac{K_{2} t q_{e}^{2}}{\left(1+K_{2} t q_{e}\right)}$

where $t(\mathrm{~min})$ is the contact time, $q_{e}$ and $q_{t}\left(\mathrm{mg} \mathrm{g}^{-1}\right)$ are the adsorption capacity at any time $t$ and equilibrium, respectively, and $K_{l}\left(\mathrm{~g} \mathrm{mg}^{-1} \mathrm{~min}^{-1}\right)$ and $K_{2}\left(\mathrm{~g} \mathrm{mg}^{-1} \mathrm{~min}^{-1}\right)$ are the rate constants of pseudo-first-order and pseudo-second-order adsorption.

\section{S5. Selective adsorption:}

To prepare various stock solutions of these metal ion, the accurate amounts of $\mathrm{UO}_{2}\left(\left(\mathrm{NO}_{3}\right)_{2} \cdot 6 \mathrm{H}_{2} \mathrm{O}, \mathrm{NH}_{4} \mathrm{VO}_{3}, \mathrm{Fe}\left(\mathrm{NO}_{3}\right)_{3} \cdot 9 \mathrm{H}_{2} \mathrm{O}, \mathrm{Co}\left(\mathrm{NO}_{3}\right)_{2} \cdot 6 \mathrm{H}_{2} \mathrm{O}, \mathrm{Ni}\left(\mathrm{NO}_{3}\right)_{2} \cdot 6 \mathrm{H}_{2} \mathrm{O}\right.$, $\mathrm{Cu}\left(\mathrm{NO}_{3}\right)_{2} \cdot 3 \mathrm{H}_{2} \mathrm{O}, \mathrm{Zn}\left(\mathrm{NO}_{3}\right)_{2} \cdot 6 \mathrm{H}_{2} \mathrm{O}$, and $\mathrm{Pb}\left(\mathrm{NO}_{3}\right)_{2}$ were dissolved completely in deionized water with the metal ions concentration of $1000 \mathrm{ppm}$. The formula of $100 \times$ co-existing spiked seawater was listed in Table S2, and Table S3 listed the concentration of metal elements in prepared $100 \times$ co-existing spiked seawater.

Table S2 The formula of $100 \times$ co-existing spiked seawater.

\begin{tabular}{cc}
\hline Stock solution & Volume/ $\boldsymbol{\mu L}$ \\
\hline $\mathrm{UO}_{2}^{2+}$ & 660 \\
$\mathrm{VO}_{3}{ }^{-}$ & 400 \\
$\mathrm{Fe}^{3+}$ & 300 \\
$\mathrm{Co}^{2+}$ & 10 \\
$\mathrm{Ni}^{2+}$ & 200 \\
$\mathrm{Cu}^{2+}$ & 120 \\
$\mathrm{Zn}^{2+}$ & 800 \\
$\mathrm{~Pb}^{2+}$ & 6 \\
Natural seawater & $2 \mathrm{~L}$ \\
\hline
\end{tabular}


Table S3 Coexisting metal ions concentration in spiked seawater prepared in this study

\begin{tabular}{cc}
\hline Element & Con. in $100 \times$ of spiked seawater $($ tested by ICP/ICP-MS $) / \mathrm{ppb}$ \\
\hline $\mathrm{U}$ & 195.2 \\
$\mathrm{~V}$ & 140.4 \\
$\mathrm{Fe}$ & 4.8 \\
$\mathrm{Co}$ & 103.9 \\
$\mathrm{Ni}$ & 73.7 \\
$\mathrm{Cu}$ & 411.5 \\
$\mathrm{Zn}$ & 10 \\
$\mathrm{~Pb}$ & $17.170 \times 10^{6}$ \\
$\mathrm{Na}$ & $1.480 \times 10^{6}$ \\
$\mathrm{Ca}$ & $0.889 \times 10^{6}$ \\
$\mathrm{Mg}$ & \\
\hline
\end{tabular}




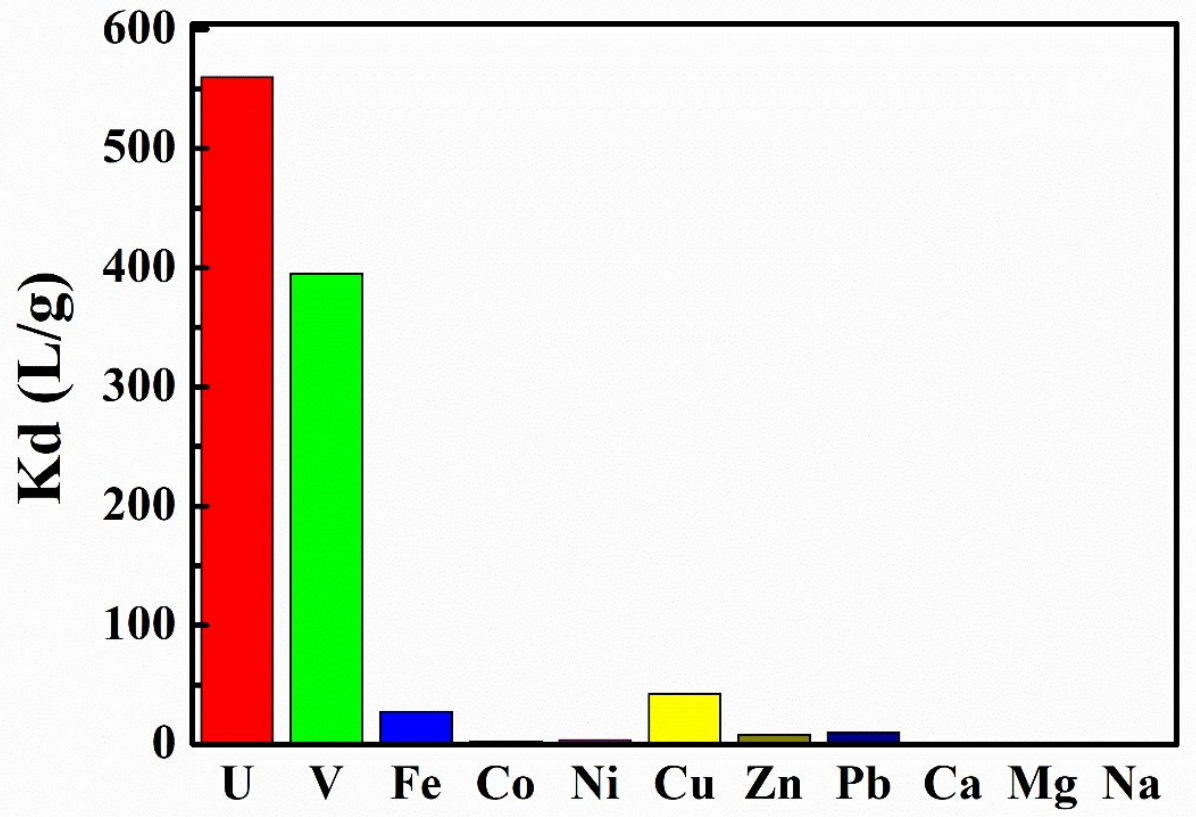

Figure S2 The distribution coefficient $(\mathrm{Kd})$ for all metal ions in $100 \times$ spiked seawater. 